\title{
Effectiveness, safety and costs of labor induction with intravaginal misoprostol versus dinoprostone vaginal insert
}

\begin{abstract}
Background: Over the last decade, a lot of clinical reviews have been published, but they are heterogeneous and present disparity of outcomes. The best choice for inducing labor is not clear today. The objective of the study is to compare misoprostol with dinoprostone for labor induction including obstetrical and neonatal outcomes, side effects and costs.
\end{abstract}

Methods and findings: From September 2012 to December 2013 a retrospective observational study was performed, including all pregnant women with medical indication of induction of labor. Three-hundred ten patients were included: 180 received $25 \mu \mathrm{g}$ of vaginal misoprostol and 130 received $10 \mathrm{mg}$ of vaginal dinoprostone. The study groups were similar with regard to age, parity, initial Bishop score and birth weight. Misoprostol group had higher percentage of entering active phase of labor within 24 hours (61.1\% versus 45.4\%; ORa=2.0 [1.3-3.3]). The cesarean section rate was lower with misoprostol (17.2\% versus $24.6 \%$; ORa $=0.6$ [0.3-1.1]). The Bishop score obtained with misoprostol was more favorable after ripening. The use of epidural analgesia was statistically higher in misoprostol group (81.7\% versus 68.5\%; ORa=2.4 [1.4-4.2]). The difference in time from the start of induction to delivery and adverse neonatal outcomes were similar in both groups. The hospital stay and the costs of hospital stay were significantly lower with misoprostol ( $€ 2690$ versus $€ 3152 ; \mathrm{pa}=0.006)$.

Conclusions: Misoprostol at doses of $25 \mu \mathrm{g}$ is more effective and more cost effective than vaginal dinoprostone, with the same safety in labor induction in women with unfavorable cervix.

Keywords: Cervical Ripening " Labor Induced " Prostaglandins " Misoprostol - Dinoprostone

Submitted: 28 April 2017; Accepted: 13 May 2017; Published online: 18 May 2017

\section{Introduction}

Induction of labor (IOL) involves the stimulation of uterine contractions to produce delivery before the onset of spontaneous labor [1]. It is currently one of the most common procedures carried in Obstetrics, having increased from $9.5 \%$ to $23.2 \%$ worldwide between 1990 and 2009 [2,3].

The success of induction of labor depends mainly on the condition of the cervix. When the cervix is unfavorable, obstetricians usually administer prostaglandins as cervical ripening agents to decrease the duration of labor and to reduce the risks of failed induction and cesarean section [4].

Dinoprostone (prostaglandin E2) has been the agent of choice for preinduction cervical ripening for several years. However,
María Asunción Quijada Cazorla*, Ana María Palacios Marqués, Josefa Marcos Sanmartín, Eduardo Cazorla Amorós, Juan Carlos Martínez Escoriza

Hospital General Universitari d'Alacant Obstetrics and gynecology department Pintor Baeza Alicante, Alicante 03010, Spain.

*Author for correspondence: asunq.cazorla@gmail.com 
it has several disadvantages: it is expensive and it requires continuous refrigeration. Misoprostol (a prostaglandin E1 analogue) is a new agent that has been approved in Spain recently for IOL. It has several potential advantages: it is stable at room temperature, it is relatively inexpensive and it has been shown to be effective and safe in stimulating uterine contractions [5].

Some studies have reported excessive uterine activity that is associated with the use of misoprostol. Various meta-analysis examining its use suggested that misoprostol was not associated with adverse fetal outcomes at a lower dose $(25 \mu \mathrm{g})[6]$.

Over the last decade, a lot of clinical trials and reviews have been published, but they are heterogeneus and present disparity of outcomes. For these reasons, the best choice for inducing labor is not clear today.

The aim of this study was to compare two protocols used in our hospital $(25 \mu \mathrm{g}$ of vaginal misoprostol versus $10 \mathrm{mg}$ of dinoprostone vaginal insert) for labor induction including: incidence of start labor with preinductor drug, cesarean section, time to achieve active labor and delivery, adverse outcomes and costs.

\section{Material and Methods}

We performed a retrospective analytical observational study. From September 2012 to December 2013 all pregnant women with medical indication of induction of labor in the Obstetrics and Gynaecology Department of the Hospital General Universitario de Alicante were enrolled. There were included: single pregnancies at term with unfavorable cervix (Bishop Score $\leq 6$ ) and medical indication to end the pregnancy. Exclusion criteria were previous cesarean section, evidence of fetal compromise, active labor period, any condition in which vaginal delivery was contraindicated (such as placenta previa) and known or suspected allergy to prostaglandin.

Baseline characteristics recorded were maternal age, parity, gestational age, indication for induction, initial Bishop score and birth weight.

Group assignment was determinate by the induction agent used. Dinoprostone (marketed as Propess ${ }^{\circ}$ ) was administered as a $10-\mathrm{mg}$ intravaginal insert, single application, and maximum for 24 hours. Fetal wellbeing is monitored every 6 hours with a 30 -minute cardiotocography (CTG). Dinoprostone was removed in the presence of fetal heart rate abnormalities, tachysystole or upon entering active phase of labor. Misoprostol (marketed as Misofar ${ }^{\circ}$ ) was administered intravaginally as a $25 \mu \mathrm{g}$ tablet every $4 \mathrm{~h}$, maximum 6 doses. A fetal CTG was performed 30 minute before and $1 \mathrm{~h}$ after its insertion. When women started active labor or intense contractions were continuosly monitored with CTG for uterine activity and fetal heart rate until delivery. If there was not adequate progression to active labor within $24 \mathrm{~h}$ or had some mild side effects, oxytocin for labor augmentation was started.

Calculation of the Bishop score was based on cervical dilation, effacement, station, position and cervical consistency. The maximum Bishop score was 13. Active labor was defined as cervical dilatation of $\geq 3 \mathrm{~cm}$ and cervical effacement $>50 \%$ in the presence of regular uterine contractions. Uterine tachysystole was defined as $>5$ contractions in a 10 -minute period and hypertonus was defined as a single contraction that lasted longer than 2 minutes. Fetal heart rate changes such us late decelerations, persistent variable decelerations, persistent brady- or tachycardia, and decreased baseline variability were indicators used to label the CTG as abnormal.

Mode of delivery, final Bishop score, epidural analgesia, presence of meconium, adverse outcomes (fever, fetal heart rate abnormalities, tachysystole or hypertonus) and neonatal outcomes (Apgar at 1 and 5 minutes, neonatal intensive care unit admission and arterial cord $\mathrm{pH}$ ) were recorded. The times from induction initiation to start active labor period and delivery were also registered. All the data were collected from the electronic medical records of each pregnant woman and each newborn.

The primary outcome was entering active phase of labor within $24 \mathrm{~h}$ with preinduction drug. Secondary outcomes measures included mode of delivery, time to active labor, fetomaternal complications, and baby Apgar scores, other possible complications (like uterine hyperstimulation, uterine rupture or fetal distress), duration of hospital stay and related costs.

The total number of patients to be included was estimated from previous studies of the working group. In the subgroup of misoprostol the frequency of initiation of the active period of labor in $24 \mathrm{~h}$ (without oxytocin) was $60.0 \%$, whereas in those treated with dinoprostone it was $44.0 \%$. With an alpha error of $5 \%$, a power of $80 \%$ and a $1: 1$ ratio between patients treated with misoprostol and those treated with dinoprostone, the number of patients to be included in each group was 152 , which makes a total of 304 patients to be included in the study.

Data entry and analysis were done with SPSS version 19.0. The chi-square test was applied for comparison of categorical factors, using the Odds Ratio (OR) with $95 \%$ confidence intervals (CI) to quantify their association and calculating adjusted OR with a 
logistical regression mode. Quantitative variables were analysed using the Mann-Whitney test, adjusted with linear regression model. Level of statistical significance was $\mathrm{p}<0.05$.

The study was conducted in accordance with current ethical and legal standards, following the bioethical guidelines of the Declaration of Helsinki. In accordance with Order SAS/3470/2009, of 16 December, publishing the directives on observational post-authorisation studies for drugs for human use, the "Agencia Española de Medicamentos y Productos Sanitarios" (AEMPS) has approved this study as a postauthorisation study with other designs. It has also been approved by our hospital's Scientific Research Ethics Committee.

\section{Results}

A total of 310 women were included; 180 received
$25 \mu \mathrm{g}$ of vaginal misoprostol and 130 patients received dinoprostone vaginal.

The study groups were similar with regard to age, parity, initial Bishop score and birth weight [Table 1]. The mean age of the women in the study group was 31.2 years. The most common reason for induction of labor was postdates pregnancy in both groups. There were differences in gestational age and indication for induction, so then adjusted statistical analysis was performed to control these confounders.

Primary outcome measures are shown in [Table 2]. Misoprostol group had higher percentage of start labor within 24 hours $(61.1 \%$ versus $45.4 \%$; ORa $=2.0$ [1.33.3]). The Bishop score obtained with misoprostol was more favorable after ripening (5.5 vs. 5; pa=0.004). The median time difference from the start of induction to delivery and adverse neonatal outcomes were found to be similar in both groups. Misoprostol group showed

\begin{tabular}{|c|c|c|c|}
\hline & $\begin{array}{l}\text { Misoprostol } \\
\quad(n=180)\end{array}$ & $\begin{array}{l}\text { Dinoprostone } \\
\quad(n=130)\end{array}$ & $\mathrm{p}$-value \\
\hline Maternal age (years) & $31.5(28-35)$ & $31(28-35)$ & 0.960 \\
\hline Gestational age (days) & $279(270-288)$ & $283(275-289)$ & 0.008 \\
\hline Parity & $1(1-2)$ & $1(1-2)$ & 0.276 \\
\hline Initial Bishop score & $2(1-3)$ & $2(1-3)$ & 0.490 \\
\hline \multicolumn{4}{|l|}{ Indication for induction: } \\
\hline $\begin{array}{r}\text { Post term (32.3\%) } \\
\text { Premature rupture of membranes }(23.2 \%) \\
\text { Oligohydramnios }(11.9 \%) \\
\text { Gestational hypertension }(4.5 \%) \\
\text { Fetal compromise }(12.6 \%) \\
\text { Intrahepatic cholestasis of pregnancy }(5.2 \%) \\
\text { Other maternal medical conditions }(5.2 \%) \\
\text { Other }(5.2 \%)\end{array}$ & $\begin{array}{c}56(31.1) \\
35(19.4) \\
21(11.7) \\
5(2.8) \\
12(6.7) \\
26(14.4) \\
13(7.2) \\
12(6.7)\end{array}$ & $\begin{array}{l}44(33.8) \\
37(28.5) \\
16(12.3) \\
9(6.9) \\
4(3.1) \\
13(10.0) \\
3(2.3) \\
4(3.1)\end{array}$ & 0.048 \\
\hline Birthweigth (grams) & $3320(2995-3707.5)$ & $3360(2957.5-3665)$ & 0.926 \\
\hline
\end{tabular}

\begin{tabular}{|c|c|c|c|c|}
\hline & $\begin{array}{l}\text { Misoprostol } \\
\quad(n=180)\end{array}$ & $\begin{array}{l}\text { Dinoprostone } \\
\qquad(n=130)\end{array}$ & $\begin{array}{c}\mathrm{p}_{c} \\
\mathrm{OR}_{c}(95 \% \mathrm{Cl})^{1}\end{array}$ & $\begin{array}{c}p_{a} \\
\mathrm{OR}_{a}(95 \% \mathrm{Cl})^{2}\end{array}$ \\
\hline $\begin{array}{l}\text { Start labor with prostaglandin } \\
\text { within } 24 \text { hours }\end{array}$ & $110(61.1)$ & $59(45.4)$ & $1.9(1.2-3.0)$ & $2.0(1.3-3.3)$ \\
\hline Final Bishop score & $5.5(4-7)$ & $5(4-7)$ & 0.062 & 0.044 \\
\hline Difference between final and initial Bishop score & $3(2-4)$ & $3(1-4)$ & 0.065 & 0.068 \\
\hline Final Bishop score $>6$ & $66(36.7)$ & $39(30.5)$ & $1.3(0.8-2.1)$ & $1.3(0.8-2.2)$ \\
\hline Spontaneous vaginal delivery & $115(63.9)$ & $68(52.3)$ & $1.6(1.0-2.6)$ & $1.4(0.8-2.3)$ \\
\hline Cesarean section rate & $31(17.2)$ & $32(24.6)$ & $0.6(0.4-1.1)$ & $0.6(0.3-1.1)$ \\
\hline Induction - start labor interval (hours) & $14(9-24)$ & $15(8-24)$ & 0.779 & 0.844 \\
\hline Induction - delivery interval (hours) & $19(13-29)$ & $22(12-31)$ & 0.908 & 0.673 \\
\hline
\end{tabular}

${ }^{1} \mathrm{p}_{\mathrm{c}}=P$ value crude; $O \mathrm{R}_{\mathrm{c}}=$ Odds ratio crude

${ }^{2} \mathrm{p}_{\mathrm{a}}=P$ value adjusted; $O \mathrm{R}_{\mathrm{a}}=$ Odds ratio adjusted 
a higher tendency of spontaneous vaginal delivery (63.9\% vs. 52.3\%; ORa $1.4[0.8-2.3])$ and a lower cesarean section rate $(17,2 \%$ vs. $24,6 \%$; $\mathrm{ORa}=0,6[0,3-$ $1,1])$, but this difference was not statistically significant [Table 3].

Regarding serious adverse outcomes, we found no statistically significant differences between two groups, although more side effects were found with dinoprostone [Table 4]. We have observed higher tendency to meconium-stained amniotic fluid with misoprostol, althought this was not statistically significant $(13.9 \%$ vs. $8 \%$; ORa $=1.8$ [0.8-4.1]). Epidural analgesia use was statistically higher in misoprostol group $(81.7 \% \mathrm{vs}$. 68.5\%; ORa=2.4 [1.4-4.2]).

There were no statistical differences between neonatal outcomes [Table 5]. A lower number of admissions to neonatal unit were recorded with misoprostol $(3.9 \%$ vs. $6.2 \%$; ORa $=0.2[0.1-0.9])$. There was no perinatal or maternal mortality in either group. The median number of days of duration of hospital stay was lower in misoprostol group ( 3 vs. 4; $\mathrm{pa}<0.001$ ); so the costs of hospital stay were also significantly lower with misoprostol (2690€ vs. 3152€; pa=0.006) [Table 6].

\section{Discussion}

Compare both prostaglandins in terms of efficacy and safety with literature is difficult. The evidence provides many meta-analyses and systematic reviews, but these include clinical trials with different dosage regimens, intervals and routes of administration, so it is difficult to draw conclusions about what prostaglandin would be most suitable or on what dose and interval administration should be used.

The Cochrane review published in 2010 [7], comparing vaginal misoprostol with vaginal

\begin{tabular}{|c|c|c|c|c|}
\hline & $\begin{array}{l}\text { Misoprostol } \\
(n=180)\end{array}$ & $\begin{array}{l}\text { Dinoprostone } \\
\qquad(n=130)\end{array}$ & $\mathrm{OR}_{c}(95 \% \mathrm{Cl})^{1}$ & $\mathrm{OR}_{\mathrm{a}}(95 \% \mathrm{Cl})^{2}$ \\
\hline Spontaneous vaginal delivery & $115(63.9)$ & $68(52.3)$ & $1.6(1.0-2.6)$ & $1.4(0.8-2.3)$ \\
\hline Cesarean section rate & $31(17.2)$ & $32(24.6)$ & $0.6(0.4-1.1)$ & $0.6(0.3-1.1)$ \\
\hline $\begin{array}{l}\text { Failed induction } \\
\text { Lack of labor progress } \\
\text { Cephalopelvic disproportion } \\
\text { Fetal distress }\end{array}$ & $\begin{array}{c}6(3.3) \\
11(6.1) \\
5(2.8) \\
9(5)\end{array}$ & $\begin{array}{c}9(6.9) \\
10(7.7) \\
5(3.8) \\
8(6.2)\end{array}$ & & \\
\hline Emergency cesarean section & $4(2.2)$ & $6(4.6)$ & $1.6(0.4-6.2)$ & $1.9(0.4-9.8)$ \\
\hline
\end{tabular}

${ }^{1} \mathrm{OR}_{\mathrm{c}}=$ Odds ratio crude

${ }^{2} \mathrm{OR}_{\mathrm{a}}=$ Odds ratio adjusted

\begin{tabular}{|c|c|c|c|c|}
\hline \multicolumn{5}{|c|}{$\begin{array}{l}\text { Table } 4 \text {. Obstetrical outcomes. } \\
\text { Values are given as } n(\%), \text { OR }(95 \% \mathrm{Cl}) \text { crude and adjusted. }\end{array}$} \\
\hline & $\begin{array}{l}\text { Misoprostol } \\
\qquad \begin{array}{c}(n=180) \\
\mathbf{n}(\%)\end{array}\end{array}$ & $\begin{array}{l}\text { Dinoprostone } \\
\qquad \begin{array}{c}(n=130) \\
\mathbf{n}(\%)\end{array}\end{array}$ & $\mathrm{OR}_{\mathrm{c}}(95 \% \mathrm{Cl})^{1}$ & $\mathrm{OR}_{\mathrm{a}}(95 \% \mathrm{Cl})^{2}$ \\
\hline Incidences during preinduction & $33(18.3)$ & $31(23.8)$ & $0.7(0.4-1.2)$ & $0.7(0.4-1.3)$ \\
\hline Abnormal FHR ${ }^{3}$ & $9(5)$ & $13(10)$ & & \\
\hline Meconium staining $\mathrm{AF}^{4}$ & $13(7.2)$ & $4(0.3)$ & & \\
\hline Uterine Tachysystole & $2(1.1)$ & $5(3.8)$ & & \\
\hline Uterine Hypertonus & $1(0.5)$ & $3(2.3)$ & & \\
\hline $\begin{array}{l}\text { Uterine hyperstimulation with } \mathrm{FHR}^{3} \\
\text { abnormalities }\end{array}$ & $3(1.7)$ & $2(1.5)$ & & \\
\hline Fever $\left(>38^{\circ} \mathrm{C}\right)$ & $3(1.7)$ & $2(1.5)$ & & \\
\hline Others & 2 nausea and vomiting & $\begin{array}{c}1 \text { cord prolapse; } \\
1 \text { abruptio placentae }\end{array}$ & & \\
\hline Secondary effects & $13(7.2)$ & $20(15.7)$ & $0.4(0.2-0.9)$ & $0.3(0.2-0.8)$ \\
\hline Uterine rupture & 0 & 0 & & \\
\hline $\begin{array}{l}\text { Meconium-stained } \mathrm{AF}^{4} \\
\text { intrapartum }\end{array}$ & $25(13.9)$ & $10(8.0)$ & $1.9(0.9-4.0)$ & $1.8(0.8-4.1)$ \\
\hline Epidural analgesia & $147(81.7)$ & $89(68.5)$ & $2.1(1.2-3.5)$ & $2.4(1.4-4.2)$ \\
\hline $\begin{array}{l}{ }^{1} \mathrm{OR}_{\mathrm{c}}=\text { Odds ratio crude } \\
{ }^{2} \mathrm{OR}=\text { Odds ratio adjusted } \\
{ }_{\mathrm{c}}=\mathrm{d} \mathrm{FH}=\text { fetal heart rate } \\
{ }^{3} \mathrm{AF}=\text { amniotic fluid }\end{array}$ & & & & \\
\hline
\end{tabular}




\begin{tabular}{|c|c|c|c|c|}
\hline & $\begin{array}{l}\text { Misoprostol } \\
\quad(n=180)\end{array}$ & $\begin{array}{l}\text { Dinoprostone } \\
\quad(n=130)\end{array}$ & $\begin{array}{c}p_{c} \\
\operatorname{OR}_{c}(95 \% \mathrm{Cl})^{1}\end{array}$ & $\begin{array}{c}\mathrm{p}_{\mathrm{a}} \\
\mathrm{OR}_{\mathrm{a}}(95 \% \mathrm{Cl})^{2}\end{array}$ \\
\hline Admission to neonatal unit & $7(3.9)$ & $8(6.2)$ & $0.6(0.2-1.7)$ & $0.2(0.1-0.9)$ \\
\hline $\mathrm{NICU}^{3}$ admission & $1(0.6)$ & 0 & - & - \\
\hline 1-minute Apgar score $<5$ & $8(4.4)$ & $5(3.8)$ & $1.2(0.4-3.6)$ & $1.0(0.3-3.4)$ \\
\hline 1-minute Apgar score & $9(9-9)$ & $9(9-9)$ & 0.926 & 0.876 \\
\hline 5-minute Apgar score & $10(10-10)$ & $10(10-10)$ & 0.576 & 0.714 \\
\hline Umbilical artery $\mathrm{pH}$ & $7.23(7.17-7.29)$ & $7.26(7.20-7.31)$ & 0.070 & 0.093 \\
\hline Umbilical artery $\mathrm{pH}<7.20$ & $30(35.7)$ & $16(23.9)$ & $1.8(0.9-3.6)$ & $1.9(0.9-4.2)$ \\
\hline Neonatal mortality & 0 & 0 & & \\
\hline
\end{tabular}

${ }^{1} \mathrm{p}_{\mathrm{c}}=P$ value crude; $\mathrm{OR}=$ Odds ratio crude

${ }^{2} \mathrm{p}_{\mathrm{c}}=P$ value adjusted; $\mathrm{OR}_{\mathrm{a}}=$ Odds ratio adjusted

${ }^{3} \mathrm{NICU}=$ neonatal intensive care unit

\begin{tabular}{|c|c|c|c|c|}
\hline \multicolumn{5}{|c|}{$\begin{array}{l}\text { Table } 6 . \text { Costs. } \\
\text { rd quartiles }), P \text { value crude }\left(p_{c}\right) \text { and } P \text { value adjusted }\left(p_{\mathrm{a}}\right) \text {. }\end{array}$} \\
\hline & $\begin{array}{c}\text { Misoprostol } \\
(n=180)\end{array}$ & $\begin{array}{l}\text { Dinoprostone } \\
(\mathrm{n}=130)\end{array}$ & $\mathrm{p}_{\mathrm{c}}{ }^{1}$ & $\mathrm{p}_{\mathrm{a}}^{2}$ \\
\hline Cost of hospital stay (euros) & $\begin{array}{c}2690 \\
(2690-3183)\end{array}$ & $\begin{array}{c}3152 \\
(2664-3445)\end{array}$ & 0.133 & 0.006 \\
\hline Duration of hospital stay (days) & $3(3-4)$ & $4(3-5)$ & $<0.001$ & $<0.001$ \\
\hline Drug preinduction cost (euros) & 1200.22 & 4950.92 & $<0.001$ & $<0.001$ \\
\hline
\end{tabular}

${ }^{1} \mathrm{p}_{\mathrm{c}}=P$ value crude

${ }^{2} p_{\mathrm{a}}=P$ value adjusted

dinoprostone, concluded that misoprostol used at higher doses of $25 \mu \mathrm{g}$ is more effective (less cesarean section) than conventional methods for the induction of labor, but has higher rates of uterine hyperstimulation. However, as our study, it shows that lower doses misoprostol $(25 \mu \mathrm{g})$ were similar to the conventional methods in terms of efficacy and risks.

The systematic review of Sánchez-Ramos [8], comparing different methods of induction of labor, concluded that the use of misoprostol was associated with a lower rate of cesarean sections but also with more tachysystole and uterine hyperstimulation. As in our study, they did not found difference in neonatal outcomes.

A more recent and specific review published by Austin [9] included only randomised clinical trials that compare the efficacy and safety of $10 \mathrm{mg}$ of dinoprostone vaginal insert with intermittent vaginal administration of misoprostol; in 8 studies misoprostol dose was $50 \mu \mathrm{g}$ an in 3 of them, it was $25 \mu \mathrm{g}$. The use of dinoprostone was associated with lower efficacy than misoprostol, with less deliveries whitin 12 and 24 hours and less need for oxytocin augmentation. Although dinoprostone was associated with an increased rate of cesarean delivery, this difference was not statistically significant. This review also demonstrated a similar safety for both drugs. Our findings for effectiveness and safety are consistent with those obtained in this review; in fact, the rate of cesarean sections were similar for both prostaglandins in these randomized trials that used misoprostol at dose of $25 \mu \mathrm{g}[5,10,11]$.

Abraham [12] which compared the efficacy of vaginal misoprostol at $25 \mu \mathrm{g}$ every $4 \mathrm{~h}$ versus dinoprostone vaginal insert in cases of premature rupture of membranes, observed that the use of vaginal misoprostol was more effective. We found similar results in our study. Rupture of membranes was the indication for induction in $23.2 \%$ of cases in our series.

There is a clear relationship between safety and the dose of misoprostol. Crane [13] and more recently Liu [14], concluded that rates of tachysystole and hypertonia are higher with misoprostol, but the majority of clinical trials included in these reviews used misoprostol at doses above $25 \mu \mathrm{g}$. Only 3 of 14 trials included in Crane's review used $25 \mu \mathrm{g}$ misoprostol.

As in our study, the clinical trials that used $25 \mu \mathrm{g}$ of misoprostol found no significant differences in the frequency of hypertonia or uterine hyperstimulation between dinoprostone and misoprostol [5,10,11]. However, Harms [10] reports a longer hospital stay and a tendency to greater post-partum complications in misoprostol group.

The presence of meconium-stained amniotic fluid deserves special mention. We found a higher prevalence 
of meconium-stained amniotic fluid with misoprostol, although this difference was not statistically significant. These results are consistent with those reported in literature [5,11]. However, this finding was not associated with worse perinatal outcomes in terms of Apgar scores, $\mathrm{pH}$ of umbilical artery or admission to neonatal unit.

As Ramsey [15] published, we believe that it is important to identify which cervical ripening agent is most cost-effective for clinical practice. We analysed the drug costs associated with the procedure used for cervical ripening, which was significantly lower in misoprostol group $(€ 1,200$ for the cost of all tablets of misoprostol versus $€ 4,950.92$ for dinoprostone inserts). We also studied the total cost associated with women hospital stay, which was also cheaper with misoprostol $(€ 2,690$ vs. $€ 3,152 ; \mathrm{pa}=0.006)$. Ramsey (Ramsey et al., 2003) also reported a significantly lower mean cost per patient for misoprostol, despite using misoprostol at a dose of $50 \mu \mathrm{g}$.

This study has several limitations. First, it is a single-center retrospective study. There was no patient randomisation. Women belonged to one or another group depending on when the induction took place: if induction had been before April 2013 only dinoprostone was available, and after this date, misoprostol that had already been approved in our hospital was used. Second, local factors such as availability of human resources, facility resources, or individual physician decision making may have influenced the decision to perform a cesarean section. On the other hand, the simple size is limited by the prevalence of inductions in our area and established inclusion criteria.

To control confounding variables and heterogeneity of the nonrandomized groups, an homogeneity and multivariate logistic regression analysis was conducted. Furthermore, the statistical calculations were made by another independent person who does not work for the gynaecology department.

Despite the exposed systematic errors, we must emphasize that the study has high internal validity and high practical application. Finally it should be noted that due to the recent approval of misoprostol in our country, there are still no national clinical trials with larger sample sizes and those available in international literature are very heterogeneous.

A prospective clinical trial will need to be performed to elucidate and subsequently generalize the findings from this study. However, our study suggests that vaginal misoprostol at dose of $25 \mu \mathrm{g}$ every 4 hours is more effective and more cost-effective than dinoprostone vaginal insert, with the same safety for the mother and the baby, for labor induction in women with unfavorable cervix.

\section{Acknowledgements}

Authors are thankful to all the team of gynecologists, residents, midwives, nurses, administrative staff and auxiliaries, who are part of the Obstetrics and Gynecology team of the Hospital General Universitario de Alicante as well as all pregnant women and their children for making this possible study.

\section{Conflict of Interest}

The authors declare that there is no conflict of interest.

\section{Executive summary}

Background: Over the last decade, a lot of clinical reviews have been published, but they are heterogeneus and present disparity of outcomes. The best choice for inducing labor is not clear today. The objetive of the study is to compare misoprostol with dinoprostone for labor induction including obstetrical and neonatal outcomes, side effects and costs.

Methods and findings: From September 2012 to December 2013 a retrospective observational study was performed, including all pregnant women with medical indication of induction of labor. Three-hundred ten patients were included: 180 received $25 \mu \mathrm{g}$ of vaginal misoprostol and 130 received $10 \mathrm{mg}$ of vaginal dinoprostone. The study groups were similar with regard to age, parity, initial Bishop score and birthweight. Misoprostol group had higher percentage of entering active phase of labor within 24 hours (61.1\% versus 45.4\%; $\mathrm{ORa}=2.0$ [1.3-3.3]). The cesarean section rate was lower with misoprostol (17.2\% versus $24.6 \%$; ORa=0.6 [0.31.1]). The Bishop score obtained with misoprostol was more favorable after ripening. The use of epidural analgesia was statistically higher in misoprostol group (81.7\% versus 68.5\%; ORa $=2.4$ [1.4-4.2]). The difference in time from the start of induction to delivery and adverse neonatal outcomes were similar in both groups. The hospital stay and the costs of hospital stay were significantly lower with misoprostol ( $€ 2690$ versus $€ 3152 ; \mathrm{pa}=0.006)$.

Conclusions: Misoprostol at doses of $25 \mu \mathrm{g}$ is more effective and more cost effective than vaginal dinoprostone, with the same safety in labor induction in women with unfavorable cervix. 


\section{References}

1. American College of Obstetricians and Gynecologists. Induction of labor: ACOG Practice Bulletin No 107. Obstet Gynecol 114: 386-397 (2009).

2. National Collaborating Centre for Women's and Children's Health. Induction of labour. Clinical Guideline. RCOG Press. ISBN-13: 978-1-904752-48-6 (2008).

3. Murthy K, Grobman WA, Lee TA, Holl JL. Trends in induction of labor at early-term gestation. Obstet Gynecol 204: 435-436 (2011).

4. Laughon SK, Zhang J, Grewal J, Sundaram R, Beaver J, Reddy UM. Induction of labor in a contemporary obstetric cohort. Obstet Gynecol 206: 486 (2012).

5. Wing DA, Ortiz-Omphroy G, Paul RH. A comparison of intermittent vaginal administration of misoprostol with continuous dinoprostone for cervical ripening and labor induction. Am J Obstet Gynecol 177: 612-618 (1997).

6. Wing DA, Lovett K, Paul RH. Disruption of prior uterine incision following misoprostol for labor induction in women with previous cesarean delivery. Obstet Gynecol 91:828-830 (1998).

7. Hofmeyr GJ, Gülmezoglu AM, Pileggi C. Vaginal misoprostol for cervical ripening and induction of labour. Cochrane Database of Syst Rev (10): CD000941 (2010).

8. Sánchez-Ramos L, Kaunitz A. Misoprostol for cervical ripening and labor induction: a systematic review of the literatura. Clin Obstet Gynecol 43: 475-488 (2000).
9. Austin SC, Sánchez-Ramos L, Adair D. Labor induction with intravaginal misoprostol compared with the dinoprostone vaginal insert: a systemativ review and mataanalysis. Am J Obstet Gynecol 202: 624 (2010).

10. Harms K, Nguyen C, Toy EC, Baker B. Intravaginal misoprosotol versus cervidil for cervical for cervical ripening in term pregnancies. Obstet Gynecol 97: 36 (2001).

11. Bolnick JM, Velázquez MD, González JL, Rappaport VJ, Mcllwain-Dunivan G, Rayburn WF. Randomized trial between two active labor management protocols in the presence of an unfavourable cervix. Am J Obstet Gynecol 190: 124-128 (2004).

12. Abraham C, Meirowitz N, Kohn N. Labor induction for premature ruptura of membranes using vaginal misoprostol versus dinosprostone vaginal insert. Am J Perinatol 31: 181-186 (2014).

13. Crane JMG, Butler B, Young DC, Hannah ME. Misoprostol compared with prostaglandin $\mathrm{E} 2$ for labor induction in women at term with intact membranes and unfavourable cervix: a systematic review. BJOG 113: 1366-1376 (2006).

14. Liu A, Lv J, Hu Y, Lang J, Ma L, Chen W. Efficacy and safety of intravaginal misoprostol versus intracervical dinoprostone for labor induction at term: a systematic review and meta-analysis. $J$ Obstet Gynaecol Res 40: 897-906 (2014).

15. Ramsey PS, Harris DY, Ogburn PL, Heise RH, Magtibay PM, Ramin KD. Comparative efficacy and cost of the prostaglandin analogs dinoprostone and misoprostol as labor preinduction agents. Am J Obstet Gynecol 188: 560-565 (2003). 